(2) Open Access Full Text Article

\title{
Intestinal schistosomiasis presenting as large bowel perforation in an HIV-positive individual
}

This article was published in the following Dove Press journal:

Research and Reports in Tropical Medicine

28 July 2011

Number of times this article has been viewed

\section{RA Cadwallader \\ N Shabalala \\ I Thirsk}

Ngwelezana Hospital, Empangeni, South Africa
Correspondence: RA Cadwallader Ngwelezana Hospital, PO Box X2002I, Empangeni 3880, South Africa

Tel +27 760557050

Fax +2735794I684

Email rosiel878@doctors.org.uk

\begin{abstract}
Endemic to over 70 countries and resulting in 200 million infected individuals and 500,000 deaths each year, the Schistosoma trematode worm can result in multisystem morbidity. Bowel obstruction secondary to this parasite has previously been described, but we report the first case of schistosomiasis affecting the sigmoid colon and resulting in perforation in a male positive for human immunodeficiency virus.
\end{abstract}

Keywords: large bowel obstruction, large bowel perforation, schistosomiasis, bowel resection

\section{Introduction}

Schistosomiasis is a relatively common finding in patients in South Africa, and the intestinal, hepatic, and urinary sequelae of parasitic invasion are well documented. Bowel obstruction has previously been reported in this patient population but, with the exception of a case from Kuwait of jejunal perforation, ${ }^{2}$ a French case of rectal perforation, ${ }^{3}$ and a case of sigmoid colonic obstruction resulting in perforation, ${ }^{4}$ there are no recorded cases of large bowel perforation in an individual positive for human immunodeficiency virus (HIV) in the literature. We report an unusual cause of large bowel obstruction with associated perforation and discuss the etiology.

\section{Case report}

A 44-year-old HIV-positive South African male presented with a short history of symptoms consistent with large bowel obstruction. Initial imaging including a plain abdominal radiograph (Figure 1), and a single contrast enema identified large bowel obstruction secondary to a stricturing lesion in the descending colon (Figure 2). A tentative diagnosis of colonic malignancy was made. Due to the patient's poor physical condition, a transverse colostomy was fashioned as a temporizing measure before optimizing the patient for definitive surgery.

Computed tomography confirmed the presence of a left-sided colonic stricture, and bladder calcification was noted retrospectively (Figure 3). Six weeks on from the original surgery, the patient returned in an improved physical state for an extended left hemicolectomy. Intraoperative findings were that of an inflammatory lesion involving the descending colon, with multiple vascular adhesions and a small localized perforation (Figure 4). The lesion was resected, the colostomy left in situ, and the distal bowel stapled. 


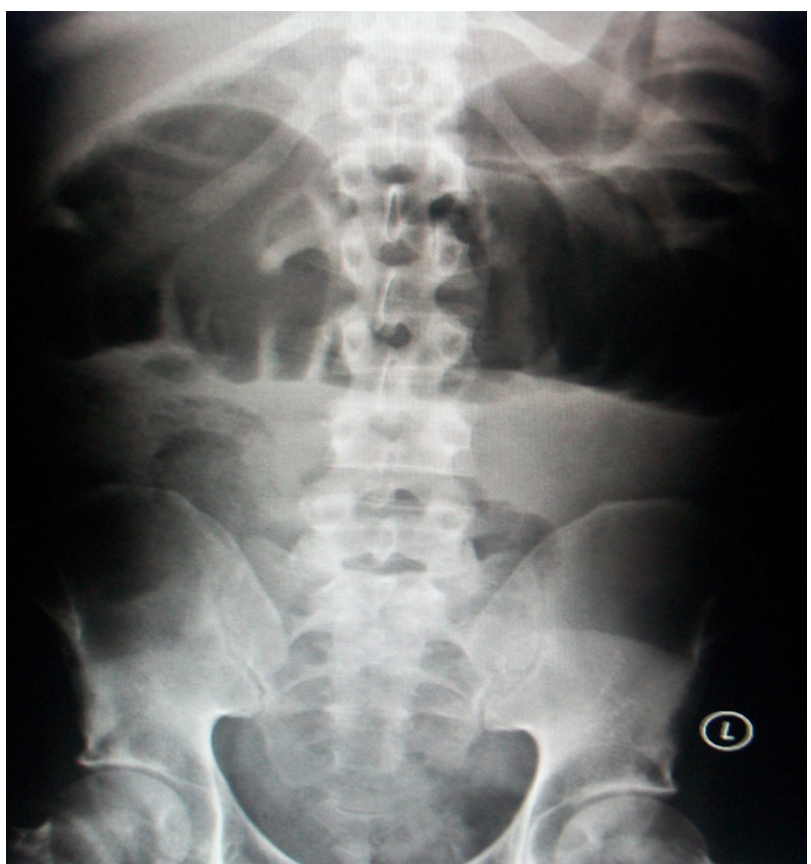

Figure I Abdominal X-ray on presentation demonstrating dilated large bowel loops.

Subsequent histopathology identified Schistosomiasis haematobium, with ova identified within the submucosa, evidence of fibrosis, and granulomatous colitis with a small localized perforation. Treatment with praziquantel was therefore implemented and the patient made an uneventful recovery.

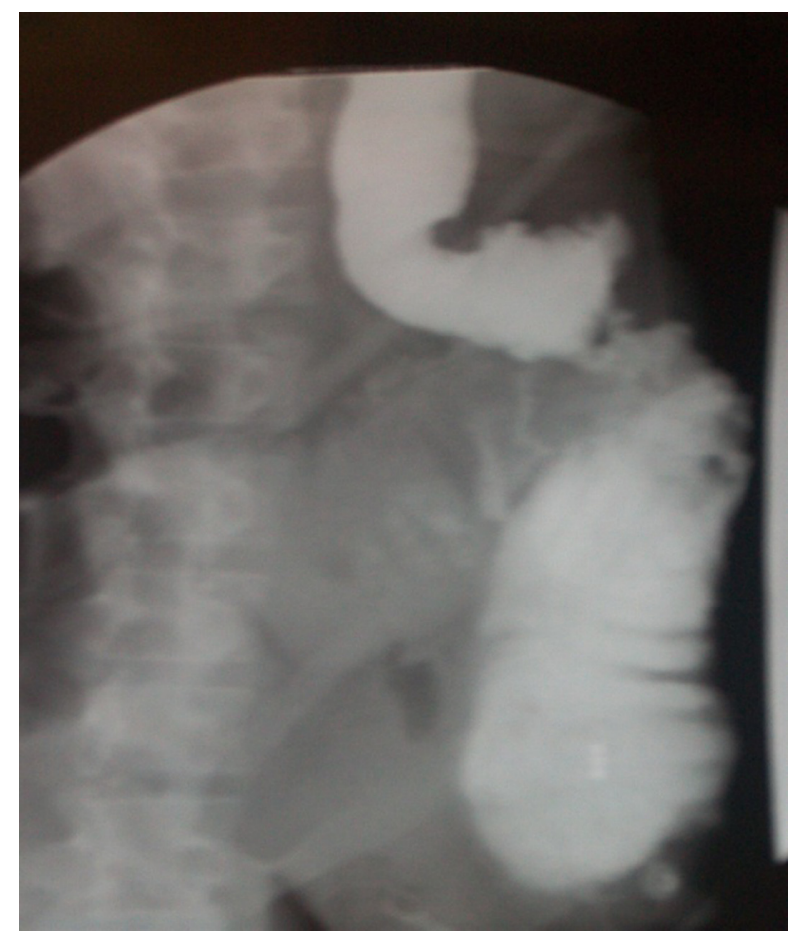

Figure 2 Single contrast enema identifying a stricturing lesion in the left colon.

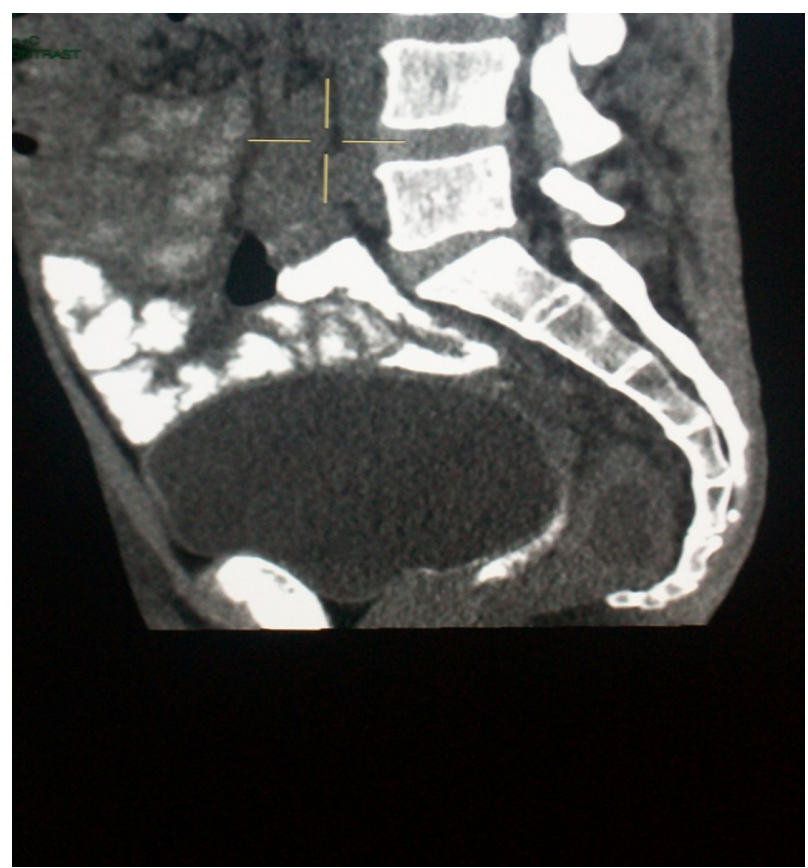

Figure 3 Computed tomography of pelvis.

\section{Discussion}

Predominantly affecting tropical and subtropical regions, schistosomiasis is transmitted by larvae-producing snails, with penetration of these larvae through the host's skin. Pathogenic subclassification (S. mansoni, S. japonicum, S. haematobium) differs between geographical regions and will govern the clinical presentation.

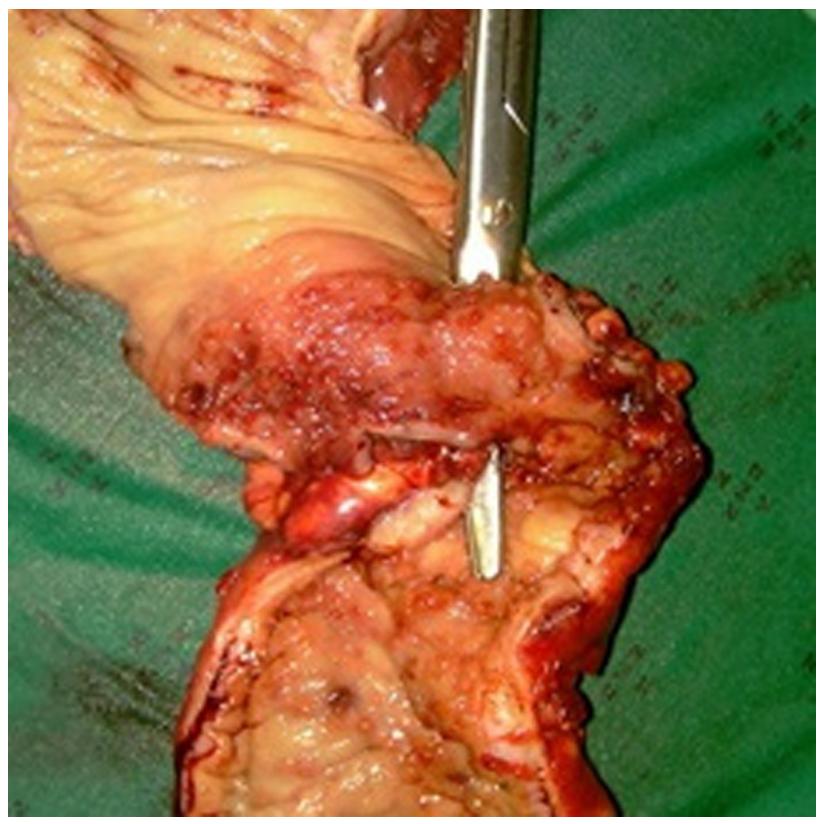

Figure 4 Left colonic specimen with instrument outlining site of perforation. 
Intestinal schistosomiasis can present in a number of ways, eg, acutely with bloody diarrhea, tenesmus, and/or abdominal pain, while chronic infection leads to granulomatous polyp formation, ${ }^{5}$ bilharziomas, larger lesions, and stricture formation. Diagnosis is made by microscopic visualization of ova in stool or rectal mucosa, and can be treated with praziquantel or oxamniquine. ${ }^{6}$

Stoever et $\mathrm{al}^{7}$ suggested that the presence of $S$. haematobium, particularly in women, led to lesions affecting the external genitalia and therefore was a lasting entry point for HIV. They suggest that treatment of schistosomiasis can subsequently reduce the risk of contracting HIV. Speculation still exists regarding the exact role of coexisting HIV and schistosomiasis infection, and Secor and Sundstrom ${ }^{8}$ suggest schistosomal infections create an immune environment that may accelerate HIV disease progression. However, further work is necessary to establish the effect on antiretroviral therapy.

\section{Disclosure}

The authors report no conflicts of interest in this work.

\section{References}

1. Schafer T, Hale B. Gastrointestinal complications of schistosomiasis. Curr Gastroenterol Rep. 2001;3:293-303.

2. Singh N, Mannan A, Kahvic M, et al. Jejunal perforation caused by schistosomiasis. Trop Doct. 2010;40:191-192.

3. Argemi X, Camuset G, Abou-Baker A, et al. Rectal perforation caused by Schistosoma haematobium. Am J Trop Med Hyg. 2009;80: 179-181.

4. Atik F, Lopes Filho G, Linhares M, et al. Large intestine obstruction complicated by perforation: A rare manifestation of Schistosoma mansoni infection. Sao Paulo Med J. 1998;116:1781-1783.

5. Smith J, Said M, Kelada A, et al. Studies on schistosomal rectal and colonic polyposis. Am J Trop Med Hyg. 1977;26:80-84.

6. Saconato H, Attalah A. Interventions for treating Schistosoma mansoni. Cochrane Database Syst Rev. 1999:(3);CD000528.

7. Stoever K, Molyneux D, Hotez P, et al. HIV/AIDs, schistosomiasis and girls. Lancet. 2009;373:2025-2026.

8. Secor W, Sundstrom J. Below the belt: New insights into potential complications of HIV-1/schistosome coinfections. Curr Opin Infect Dis. 2007;20:519-523.
Research and Reports in Tropical Medicine

\section{Publish your work in this journal}

Research and Reports in Tropical Medicine is an international, peerreviewed, open access journal publishing original research, case reports, editorials, reviews and commentaries on all areas of tropical medicine, including: Diseases and medicine in tropical regions; Entomology; Epidemiology; Health economics issues; Infectious disease; Laboratory

\section{Dovepress}

science and new technology in tropical medicine; Parasitology; Public health medicine/health care policy in tropical regions; and Microbiology. The manuscript management system is completely online and includes a very quick and fair peer-review system. Visit http://www.dovepress. com/testimonials.php to read real quotes from published authors. 